\title{
As organizações religiosas e suas relações: Uma análise a partir da teoria dos stakeholders
}

\author{
Religious organizations and their relationship: An analysis from the stakeholders' \\ theory
}

Maurício Custódio Serafim

Universidade do Estado de Santa Catarina - UDESC

Graziela Dias Alperstedt

Universidade do Estado de Santa Catarina - UDESC

e-mail: graziela@udesc.br

Artigo Recebido em 19.07.2011. Revisado por pares em 12.11.2011. Recomendado em 12.11.2011 por Edson Roberto Scharf, Editor Responsável. Publicado em 30.06.2012. Organização responsável pelo periódico: FURB Universidade de Blumenau (www.furb.br/rn)

\begin{abstract}
Resumo
As organizações religiosas tais como outros tipos de organizações, tem passado por um processo de transformação. A pressão por resultados leva a uma racionalização dessas estruturas. Essa racionalização possibilita o cumprimento do seu objetivo organizacional de forma eficaz e o planejamento de estratégias futuras, expressando-se, principalmente, no fenômeno da burocracia. O objetivo deste artigo é propor a abordagem denominada teoria dos stakeholders para analisar as mudanças nas organizações religiosas, por se acreditar que ela seja capaz de ajudar a compreender, por um lado, a intrincada relação entre a lógica capitalista e a doutrina religiosa e, por outro, abordar a igreja como empresa a partir da perspectiva dos relacionamentos com outros atores situados no mesmo campo social. Apoiados na teoria dos stakeholders, nos argumentos de Berger (2004) e no modelo de Phillips (2007), os autores propõe um modelo para a análise das relações entre as organizações religiosas e seus stakeholders, respondendo positivamente à pergunta formulada sobre a possibilidade de utilização da teoria dos stakeholders para organizações religiosas.
\end{abstract}

Palavras-chave: Teoria dos stakeholders, organizações religiosas, burocracia.

\section{Abstract}

Religious organizations such as other types of organizations, has gone through a transformation process. The pressure for results leads to a rationalization of these structures. This streamlining allows the completion of its organizational goal of effectively and planning future strategies,

expressing itself mainly in the phenomenon of bureaucracy. The aim of this paper is to propose the approach called stakeholder theory to analyze the changes in religious organizations because believe it to be able to help to understand, on the one hand, the intricate relationship between the capitalist logic and religious doctrine, and secondly, to address the church as a company from the perspective of relationships with other actors located in the same social field. Backed by the theory of stakeholders, the arguments of Berger (2004) and the model of Phillips (2007), the authors propose a model for the analysis of relations between religious organizations and their stakeholders, responding positively to the question raised about the possibility of using stakeholder theory to religious organizations.

Keywords: stakeholder theory, religious organizations, bureaucracy.

\section{Introdução}

Historicamente, a organização religiosa exerceu forte influência sobre as empresas modernas, servindo de base para 
a organização de estruturas hierárquicas, normas, regras e o controle social, por meio dos valores apregoados (WEBER, 2004). Todavia, apesar da importância histórica e atual da imbricada relação entre vida religiosa e vida econômica, parece que ainda há certa resistência na academia em se considerar a religião, e as organizações que a representam, como um elemento da cultura tão fundamental como qualquer outro, no que tange à vida econômica.

Em particular, no campo da Administração, há um vácuo de conhecimento sobre o tema, apesar de que, desde Max Weber, sabe-se que a organização religiosa é capaz de influenciar as motivações, valores, hábitos, critérios de tomada de decisão, formas de comportamento no trabalho e de consumo. Afinal, foi a partir de uma seita protestante que o mundo conheceu o "espírito do capitalismo", mudando a dinâmica organizacional e mundial com o trabalho metódico e a busca pela eficiência, o que influenciou de forma decisiva e definitiva o vetor concorrencial entre as empresas capitalistas.

Weber analisou as implicações da irônica racionalização para a diferenciação da religião e outras instituições e suas esferas de valor (CHAVES, 1992). Após Weber, houve uma lacuna no campo no que tange às pesquisas sobre o tema. Recentemente, tem havido uma retomada dos estudos concernentes às organizações religiosas voltadas aos mais diversos temas ligados à administração, como estratégias competitivas das organizações religiosas (MILLER, 2002), organizações religiosas (CHAVES, 1992; 2002), o lugar da espiritualidade nas teorias organizacionais (OLIVEIRA, 2004), e a empresarização do sagrado (GONÇALVES; SERRA; COSTA, 2007), dentre outros.

Gonçalves, Serra e Costa (2007, p. 1), por exemplo, chamam a atenção para a "crescente complexidade das práticas e abordagens administrativas, traduzidas na construção de novos modelos e concepções teóricas", representando um desafio para as organizações de natureza substantiva que sentem, cada vez mais, a necessidade de tornarem-se eficientes e eficazes. Nesse sentido, a dimensão econômica, passa a invadir o espaço do sagrado, determinando a necessidade da busca de uma maior capacidade gerencial e estratégica dessas organizações, levando-as a "buscar modelagens mais condizentes com aquelas do setor empresarial".

De fato, Oliveira Júnior (2002) observou as transformações que vem ocorrendo nas organizações religiosas, tais como a profissionalização do pessoal, a captação de recursos financeiros, a busca de apoio por parte de empresários e do governo, a captação de fiéis, dentre outras características. Tal constatação remete à necessidade que esse tipo de organização vem tendo no sentido de administrar sua relação com suas partes interessadas.

Haja vista a evidente preocupação das organizações religiosas em ampliar sua participação no "mercado religioso" por meio do gerenciamento da sua relação com as partes interessadas, esse artigo objetiva responder ao seguinte questionamento: a teoria dos stakeholders, inicialmente desenvolvida para organizações econômicas, é adequada para ser aplicada às organizações religiosas?

A resposta a esse questionamento pode auxiliar na compreensão de grupos de pesquisadores curiosos em acompanhar as transformações dos relacionamentos com as partes interessadas, idéia inicialmente oriunda da área de negócios, aplicadas a campos organizacionais tradicionalmente distantes do mercado. Admite-se, assim, a idéia de que as organizações religiosas não escaparam à expansão da lógica de mercado, demonstrando sinais crescentes de adequação a parâmetros empresariais (MARIANO, 1999).

Assim, o presente ensaio teórico possui como escopo a comparação entre a 
vida econômica e a vida religiosa, tendo como objetos de estudo as organizações econômica e religiosa. Nesse sentido, no âmbito da teoria das organizações, foi utilizada a teoria dos stakeholders por três motivos principais. $\mathrm{O}$ primeiro motivo se evidencia em função de que a teoria se concentra especialmente nas relações entre os grupos que compõe a organização ou que possuem interesses em jogo (at stake); o segundo, porque se acredita ser uma das teorias que melhor abordam a relação organização-sociedade, fundamental para a análise da relação das esferas econômicas e religiosas; e, o terceiro, pelo fato desta teoria considerar explicitamente a dimensão ético-normativa, o que pode ser útil quando se aborda organizações religiosas porque elas sempre possuem alguma doutrina normativa de relacionamento com o mundo.

\section{A natureza das organizações religiosas}

As organizações religiosas buscam estabelecer, incentivar e regular as relações entre os seres humanos e as divindades, ordens sobrenaturais ou princípios metafísicos supremos. Elas possuem muitas variações, mas como pontos em comum promovem adorações, orações, meditação, doutrina, curas, e bem-estar espiritual de acordo com revelações, textos, códigos, leis e princípios. Em relação ao seu tamanho, podem variar de grupos de pessoas que consultam curandeiros, gurus, à burocracias eclesiásticas de alcance mundial, como a Igreja Católica Romana (BECKFORD, 2004).

Os produtos das organizações religiosas são também muito diversos. Podem ser citados o conhecimento sagrado, experiências transcendentais, profecias, cultos e meditação, ritos com poder purificador, ritos de passagem, ética religiosa, missões de recrutamento, assistência social e solidariedade local. Os elementos em comum que possuem com as organizações não religiosas incluem a necessidade de assegurar recursos adequados, treino e controle de seu pessoal, preservação da autoridade, a convivência com conflitos e dissensões, interação com outras organizações no seu ambiente, defesa de sua parte no mercado religioso, além da luta contra os free riders e takeovers indesejados. Com o intuito de expandir e proteger suas fronteiras organizacionais, essas organizações têm criado escolas, seminários, hospitais, organizações de assistência social, editoras e ordens missionárias (BECKFORD, 2004), além do apoio a empresas com fins lucrativos.

Segundo Miller (2002), os sociólogos Rodney Stark e William Bainbridge oferecem uma ajuda na clarificação da definição dos produtos das organizações religiosas. Para eles, as organizações religiosas são empresas sociais que primam pelo propósito de criar, manter e trocar compensações gerais baseadas no sobrenatural. Essa definição aparece em paralelo à definição de religião que se caracteriza por ser um sistema de compensações gerais baseados nas crenças sobrenaturais. Esses conceitos, por sua vez, levam à distinção entre recompensas e compensações. Recompensas seriam coisas humanas que incorrem em custos para se obter. Já as compensações são postulados sobre recompensas a partir de explicações que não são facilmente suscetíveis a avaliações inequívocas.

Assim, o produto principal das organizações religiosas é a provisão de compensações sobrenaturais, as quais vêm acompanhadas com recompensas temporais. Embora clubes e outras organizações sociais possam conferir produtos que competem com as organizações religiosas, as compensações sobrenaturais são produtos distintos, para os quais não há substitutos seculares diretos (MILLER, 2002).

Chaves (2002) propõe uma pertinente distinção entre as organizações religiosas. Define congregação como organizações e coletividades locais de relativa 
pequena escala por meio das quais pessoas se engajam em atividades religiosas. São igrejas, sinagogas, mesquitas e templos, entre outros. Organizações denominacionais são organizações religiosas que servem a, são apoiadas por, ou têm autoridade sobre as congregações locais e possuem uma governança em comum. Algumas vezes podem ser entendidas como confederações de organizações relativamente autônomas. Podem, ser citados como exemplo as dioceses católicas, agências missionárias, ofícios regionais e nacionais de denominações, entre outras. Organizações sem fins lucrativos de orientação religiosa são organizações religiosas que atuam em atividades não religiosas como qualquer outra organização secular sem fins lucrativos. São, por exemplo, escolas, hospitais, creches, programas de reabilitação de dependentes químicos, e dedicadas à filantropia. Esta distinção, num certo sentido é ao mesmo tempo ampla - porque muitas das organizações das outras duas distinções também podem ser incorporadas como organizações sem fins lucrativos - e restritas, porque muitas organizações religiosas que atuam nestas áreas são organizações com fins lucrativos (como um canal de televisão).

Chaves (2002) ainda alerta que muitas organizações religiosas podem ser distinguidas por meio dessas nomeações, mas é possível, como assinalado acima, que uma organização possa ser inserida em mais de uma dessas categorias. Apesar de essa distinção conter limites, será útil por chamar a atenção das diferentes manifestações das organizações religiosas.

Outra peculiaridade é indicada por Zaleski e Zech (1995). Os autores afirmam que as congregações religiosas exibem uma rara combinação no setor sem fins lucrativos: as atividades de benefícios mútuos são apoiadas por contribuições voluntárias. E essa participação de outros, como aponta Miller (2002), produz exter- nalidades positivas para os membros das organizações religiosas, evitando a sobreposição de custos. Todavia, para realizar as externalidades positivas, essas organizações devem resolver o problema clássico da ação coletiva, ou seja, participação motivadora e controle dos free riders.

\section{A teoria dos stakeholders e seu modelo de análise}

O termo stakeholder foi cunhado em 1963 em um memorando interno do Stanford Research Institute e se referia a "grupos que sem o seu apoio a organização deixaria de existir" (FREEMAN; REED, 1983, p. 89). A idéia que embasa esta concepção é bastante simples: além dos acionistas (e/ou proprietários), a organização também é responsável por outros grupos que possuem interesses nas ações da organização. A lista inicial incluía os acionistas, funcionários, consumidores, fornecedores, financiadores e sociedade. $\mathrm{O}$ termo stakeholder, popularizado mais tarde no meio acadêmico pelos trabalhos de Freeman e Reed (1983) e Freeman (1984) é um claro trocadilho com o termo stockholder (acionista). Esses autores propõem duas definições de stakeholder: um amplo e outro mais estrito. O primeiro afirma que stakeholder é todo grupo ou indivíduo que influencia ou é influenciado pelo alcance dos objetivos da organização. $\mathrm{O}$ segundo se refere a indivíduos ou grupos que a organização depende para a sua sobrevivência. A definição mais ampla do termo é adotada por muitos autores como clássica e serve como ponto de partida para suas análises ou críticas (cf. DONALDSON; PRESTON, 1995; MITCHELL; AGLE; WOOD, 1997; FREEMAN; WICKS; PARMAR; MCVEA, 2004; PHILLIPS, 2007; PHILLIPS; FREEMAN; WICKS, 2007).

Mitchell, Agle e Wood (1997) fazem a distinção entre a abordagem e a teoria stakeholder. A primeira diz respeito 
ao entendimento da organização em seu ambiente e tem a intenção de ampliar a visão do campo da Administração acerca de seus papéis e responsabilidades que vão além da função da maximização do lucro, incluindo interesses e direitos de grupos de não-acionistas e/ou de não-proprietários. A teoria stakeholder tenta articular de forma sistemática a seguinte questão fundamental: que grupos são stakeholders que merecem ou requerem atenção da gestão?

Para Post (2006), a abordagem pretende fazer uma revisão do conceito de corporação. Ele parte do reconhecimento que a corporação é uma instituição de grande impacto econômico e social e que têm crescido em tamanho e número em todo o mundo devido a sua habilidade para mobilizar recursos e criar novas riquezas. Afirma que as transformações por que tem passado as corporações no último quartel do século requer sua redefinição enquanto instituição social. De fato, como observa D'Orazio (2006), a abordagem stakeholder procura fazer essa redefinição por meio de uma representação de empresa que a considera não apenas como uma série de transações de mercado, mas adicionalmente como um esforço cooperativo e competitivo que envolve um amplo número de indivíduos e grupos organizados. Nessa concepção, a empresa é uma organização por meio da qual diferentes indivíduos e grupos tentam atingir seus próprios fins. $\mathrm{Ou}$, dito de outra forma, a empresa é considerada como uma instituição que reconhece e utiliza seus vínculos com os múltiplos stakeholders como um meio para que ambos - empresa e stakeholders - mantenham suas capacidades de criação de riqueza e de prestação de serviço à sociedade (POST, 2006). E é nessa consideração que está embasada a legitimidade da corporação sua "licença para operar" na sociedade -, que de acordo com Post (2006), depende tanto de seu bom êxito na criação de riqueza quanto de sua habilidade de satisfazer as expectativas dos stakeholders da organização. A empresa, como uma instituição social no mundo contemporâneo, deve estar engajada na mobilização de recursos para criar riquezas e benefícios para todos os seus stakeholders.

Para Freeman, Wicks e Parmar (2004), o principal motivo para o desenvolvimento da abordagem foi procurar oferecer uma alternativa às limitações das estruturas de negócios tradicionais que não conseguiam responder satisfatoriamente a certas questões, tais como a criação de novas oportunidades num ambiente turbulento, ou seja, em um ambiente com transformações políticas e acelerado desenvolvimento tecnológico. No entender dos autores, para essa superação foi necessária que a abordagem concebesse os negócios além de sua tradicional raiz econômica, considerandoos como criação de valor para os stakeholders, como já mencionado.

Do ponto de vista gerencial, a abordagem leva em consideração ao longo do tempo os interesses legítimos desses grupos e acredita que o negócio que desconsiderar sistematicamente tais interesses provavelmente colocará sua sobrevivência em risco. Os autores ainda afirmam que a corrente dominante do pensamento administrativo pergunta a questão errada, ou seja, como deveríamos distribuir os ônus e os benefícios entre os stakeholders? Do ponto de vista da gestão stakeholder, a questão - denominada de "criação de valor" - passa a ser: como criar tanto valor quanto podemos para todos os nossos stakeholders?

Martinelli (2006) ainda afirma que a abordagem stakeholder tem sido estimulada pela crescente relevância de recursos intangíveis - tais como conhecimento, capital humano, capital social, propriedade intelectual, reputação e confiança - em que estão envolvidas todas as relações stakeholders. De fato, Post (2006) argumenta que as relações e vínculos favoráveis com os stakeholders são recursos da empresa, tanto que recursos intangíveis 
como o "capital relacional" estão se tornando importantes para a determinação do valor total de uma empresa. $\mathrm{O}$ autor cita a pesquisa da empresa de consultoria Accenture - na qual mostra que a contribuição de recursos intangíveis pode variar entre $33 \%$ a $70 \%$ da valorização da empresa - para sugerir que essa tendência dá suporte à proposta que as relações stakeholder podem se materializar em recursos econômicos para a empresa.

Entretanto, D'Orazio (2006) e Martinelli (2006) afirmam que a visão dominante do mundo dos negócios ainda é a do lucro como a única meta legítima da empresa e os acionistas (shareholders) e investidores os únicos a quem os gerentes devem responder. A predominância da dimensão econômica, tanto do objetivo da empresa quanto de seus agentes, é ampla e pode ser ilustrada pelo especial da revista The Economist de janeiro de 2005 que, ao tratar da responsabilidade social corporativa (RSC), retoma teses conhecidas contrárias ao movimento da RSC e à abordagem dos stakeholders, como as do economista Milton Friedman, que considera que a função exclusiva dos negócios é a geração de lucros para os acionistas. $\mathrm{O}$ especial é finalizado com uma frase que expressa bem o ponto de vista dos textos: "The proper business of business is business. No apology required" (CROOK et al., 2005, p. 18).

Mesmo com tais divergências, a abordagem stakeholder se popularizou entre acadêmicos, gerentes e alguns círculos políticos, sendo acompanhado por um desenvolvimento considerável da teoria dos stakeholders (D'ORAZIO, 2006). Como mencionado anteriormente, a discussão sobre a teoria tem uma questão de fundo comum: quais ou quem são os grupos stakeholders da empresa e quais ou a quem se deve dar atenção? Resumidamente, pode-se considerar que grande parte dos autores que se ocupam da teoria procura responder ao que Mitchell, Agle e
Wood (1997) denominam de "problema da identificação dos stakeholders".

Uma contribuição é a de Clarkson (1995). Diferentemente de Freeman, que propôs uma definição ampla (veja parágrafos anteriores), Clarkson (1995) propõe uma definição mais estrita em termos de "portadores de risco" e diferencia os stakeholders entre primários e secundários. Para o autor, stakeholders primários são aqueles que sem sua contínua participação a organização não poderá sobreviver. Eles fornecem a infra-estrutura, o mercado, as leis e regulamentações que devem ser obedecidas, para quem os impostos e outras taxas são devidas, e são geralmente os acionistas, investidores, funcionários, consumidores, fornecedores, e governo. Há um alto grau de interdependência entre a organização e os stakeholders primários. Os stakeholders secundários são definidos por Clarkson (1995) como aqueles que influenciam/afetam ou são influenciados/afetados pela organização, mas que não são essenciais para a sua sobrevivência, podendo ocasionalmente causar algum tipo de prejuízo ou favorecimento via stakeholders primários. Por exemplo, o autor cita a mídia, que pode mobilizar a opinião pública a favor ou contra o desempenho da empresa.

Outra contribuição para o problema da identificação é a de Donaldson e Preston (1995), que propõem uma taxonomia dos tipos de teoria dos stakeholders com o intuito de oferecer mais precisão à discussão. O primeiro tipo os autores denominam de descritivo/empírico e se refere à teoria usada para descrever e, algumas vezes, para explicar características e comportamentos específicos das empresas. O segundo tipo é a instrumental que, em conjunto com a abordagem descritiva/empírica e seus dados disponíveis, é usado para examinar as conexões entre a gestão stakeholder e o alcance dos objetivos corporativos tradicionais (como $\mathrm{o}$ crescimento, lucratividade). Ela é hipo- 
tética, no sentido da seguinte sentença: "se quiser alcançar (ou evitar) os resultados $X$, $\mathrm{Y}$, ou $\mathrm{Z}$, então adote (ou não adote) princípios e práticas A, B ou C". O terceiro tipo, denominado de normativo, refere-se à teoria usada para interpretar a função da corporação, incluindo a identificação de diretrizes morais ou filosóficas para a operação e gestão de empresas. Ela é categórica, no seguinte sentido: "faça (ou não faça) isso porque é o certo (ou errado) a se fazer" (DONALDSON; PRESTON, 1995).

Para os objetivos deste trabalho, as duas abordagens da teoria que interessam são a descritiva - cuja discussão mais adiante será importante para que seja proposto um modelo de análise - e a normativa, por se acreditar que essa abordagem seja adequada quando se trata de organizações religiosas. Entretanto, mesmo fazendo esta diferenciação, se verá que um modelo de análise almejado deverá ser um híbrido descritivo-normativo devido ao caráter ético da teoria, ou seja, as relações como são e como devem ser se complementam. Dessa forma, ao mesmo tempo em que são descritas algumas características da teoria o modelo ganha forma.

Donaldson e Preston (1995) afirmam que, embora as abordagens descritiva e instrumental sejam significativas para a teoria, sua base fundamental é normativa e requer aceitar as seguintes idéias: (a) stakeholders são pessoas ou grupos com interesses legítimos em aspectos substantivo e/ou procedural da atividade corporativa e são identificados por seus interesses na corporação se a corporação tem qualquer correspondente interesse funcional neles; (b) Os interesses de todos os stakeholders possuem valores intrínsecos. Isso significa que cada grupo de stakeholders merece ser considerado como um fim em si mesmo, e não apenas por causa de sua habilidade para promover os interesses de alguns outros grupos, tais como os acionistas.
Phillips, Freeman e Wicks (2007) reforçam esse aspecto ao afirmarem que a teoria dos stakeholders se distingue das teorias tradicionais de management porque considera explicitamente valores morais como centrais na gestão das organizações. São examinados criticamente tanto os fins quanto os meios. Dessa forma, a teoria é ao mesmo tempo de estratégia gerencial e ética. Os autores fazem um resumo das justificativas normativas vinculadas à teoria dos stakeholders, entre as quais o direito de propriedade (DONALDSON; PRESTON, 1995), o kantismo (EVAN; FREEMAN, 1993) e o princípio da equiidade (PHILLIPS, 2003), para deixar claro que apesar da teoria possuir similitudes com outras, como a teoria da dependência de recursos, a questão central que a diferencia é o dever de estar atento aos interesses e bem-estar de alguns grupos que sobrepuja os fins instrumentais relacionados com a maximização do lucro. Ainda que existam grupos stakeholders cujo relacionamento com a organização permaneça instrumental - em grande parte devido ao poder que exercem - existem outros stakeholders legítimos do ponto de vista normativo.

Os elementos poder e legitimidade são abordados por Mitchell, Agle e Wood (1997). Segundo os autores, poder e legitimidade de direitos dos stakeholders são tratados pela bibliografia como explicações rivais do status stakeholder. Eles chamam a atenção que esta rivalidade conceitual entre poder e legitimidade é refletida na maioria das teorias da firma, particularmente nas teorias da agência, comportamental, institucional, ecologia populacional, dependência de recursos e custos de transação. A teoria dos stakeholders que os autores defendem procura ir além dessa rivalidade e mostrar como interagem poder e legitimidade e, quando combinado com a categoria "urgência" (urgency), são criados diferentes tipos de stakeholders com diferentes padrões comportamentais esperadas em relação à firma. 
Para isso, os autores, em consonância ao que foi abordado anteriormente, afirmam que para responder a questão "quais são os stakeholders da organização" é requerida uma teoria normativa de identificação stakeholder. Eles propõem uma teoria da identificação capaz de reconhecer classes de stakeholders por meio de três atributos: (1) poder dos stakeholders de influenciar a empresa; (2) legitimidade (moral) da relação dos stakeholders com a empresa; (3) urgência da reivindicação dos stakeholders sobre a empresa. Esses atributos combinados formam sete classes diferentes de stakeholders e são embasadas na questão normativa porque são entidades a quem os gerentes deveriam prestar atenção. A tese dos autores é que para melhor compreender o problema de identificação torna-se necessário considerar sistematicamente a relação stakeholdergerente em termos de ausência ou presença relativa de todos ou de alguns desses atributos.

Apesar de ser uma teoria bastante completa e útil para a identificação dos stakeholders, não será utilizada nesse trabalho por ter como fundamento a abordagem cognitiva (ibidem, p. 871), o que significa que em última instância é o gerente quem determina quais serão os stakeholders que terão atenção ou, mais precisamente, a percepção dos atributos de um stakeholder pelo gerente. $\mathrm{O}$ que se procura, no trabalho em questão, é uma solução que se aproxime mais da abordagem da sociologia econômica, como a teoria das redes para o problema da descrição sistemática. Mas mesmo com essa ressalva, o trabalho de Mitchell, Agle e Wood (1997) é importante, para os propósitos deste artigo, por ter destacado a base normativa da teoria, pela discussão sobre poder e legitimidade e, principalmente, pela descrição das características dos atributos dos stakeholders e que serão adotados neste trabalho: (1) os atributos dos stakeholders são variáveis e não possuem um estado fixo; (2) os atributos dos stakeholders são realidades socialmente construídas. Essas duas características proporcionam a dinâmica do modelo ao longo do tempo.

Voltando agora a outro ponto, a legitimidade tem um papel importante na questão da identificação normativa dos stakeholders. Tanto que Phillips (2007) afirma que uma base comum em quase todas as definições de stakeholder é a noção de que seja um indivíduo ou grupo considerado como objeto legítimo da atenção do gerente ou organização. Portanto, é importante uma maior clareza sobre a definição de legitimidade, sobre o mérito de tal status e quais são afinal os grupos e indivíduos que podem ser considerados legítimos pela organização. Mas, antes disso, é preciso abordar a relação empresa-sociedade, descrita a seguir.

De uma maneira ampla é possível argumentar que a empresa - por se situar em uma sociedade, usar seus recursos e influenciar uma comunidade - deve tornarse socialmente responsável, prestando contas e fazendo contribuições que vão além de seu objetivo estritamente econômico. Em outras palavras, a empresa também deve se comprometer com questões sociais. Para Clarkson (1995), esse tipo de raciocínio é prejudicado porque a discussão sobre a relação entre as organizações e a sociedade tem tido dificuldades de considerar de modo preciso o que é uma questão social. Para o autor, essa dificuldade pode ser atribuída em parte ao significado amplo, e muitas vezes vago, da palavra social e a sua evocação à sociedade, o que leva a discussão a um nível mais abstrato e ambíguo que a empresa em si.

Com o intuito de desfazer essa ambigüidade, Clarkson (1995) sugere três níveis de análise ao abordar a relação organizações e sociedade: o institucional, apropriado para discussões de responsa- 
bilidade e prontidão social corporativa; o nível organizacional, identificado como o das empresas e grupos stakeholders - o mais apropriado para análises e avaliação de desempenho social corporativo; e o nível individual, em que o gerente lida com questões stakeholders e seu relacionamento, sendo o mais apropriado para se analisar e avaliar o desempenho gerencial. Para o propósito deste estudo, será adotado o nível de análise organizacional, o que significa, como mostra Clarkson (1995), que a questão da relação empresasociedade se traduz em relação empresa (organização)-stakeholders.

Feita essa primeira delimitação, o segundo ponto a ser tratado é a dimensão da legitimidade, como anunciada anteriormente. Uma fonte importante de legitimidade dos stakeholders estaria no fato de que são grupos e indivíduos que são afetados - de forma voluntária ou involuntária - pela atividade empresarial (POST, 2006). Os grupos e indivíduos voluntários são os acionistas, funcionários e consumidores e a palavra-chave que os define é reciprocidade, pois todos esperam ganhar com o êxito da empresa ao criar nova riqueza por meio de ganhos de produtividade, inovação e aumento da aceitação no mercado. $\mathrm{O}$ envolvimento como grupo voluntário está no aceite e cooperação nas mudanças necessárias para a continuação do êxito, apoiado na percepção de verem o benefício como resultado. Indivíduos e grupos involuntários são aqueles influenciados pelas ações da empresa de forma involuntária, particularmente aquelas sujeitas a externalidades, tais como poluição ou congestionamento, ou impactos culturais que não são bem-vindos. A principal meta é a redução ou evitação do prejuízo, ou a geração de benefícios compensatórios (POST, 2006).

Phillips (2007) problematiza essa questão e afirma que a literatura é bastante ambígua em sua abordagem sobre a legitimidade dos stakeholders. $\mathrm{O}$ autor mostra que a ambigüidade se manifesta no debate "perspectiva ampla versus perspectiva estrita" (FREEMAN; REED, 1983; MITCHELL; AGLE; WOOD, 1997; veja parágrafos anteriores). A perspectiva ampla se refere à definição de Freeman (1984) "aqueles que influenciam ou são influenciados pelo alcance dos objetivos da organização" e à intuição que a teoria deveria ser ampla o bastante para abarcar o maior número possível de stakeholders. Entretanto, segundo o autor, essa definição ampla ameaça a teoria porque não realiza as diferenciações essenciais que é preciso fazer, principalmente em termos morais. Diferentemente, a perspectiva estrita conclui que somente os grupos para os quais há uma obrigação moral é que devem ser considerados stakeholders, eliminando do quadro grupos importantes como a concorrência e a mídia. Essa perspectiva é mais utilizada por pesquisadores que adotam a concepção normativa da teoria (DONALDSON; PRESTON, 1995; PHILLIPS, 1997). Como a teoria dos stakeholders propõe ser tanto gerencial quanto ética, não incluir grupos potenciais com poder de ajudar ou dificultar o alcance dos objetivos da organização limitaria a teoria.

Phillips (2007) continua sua análise fazendo uma crítica ao trabalho de Mitchell, Agle e Wood (1997) e mostra que é problemático se fazer referência a grupos com poder com os quais não se têm obrigações morais, mas que podem influenciar de modo significativo a organização, como um grupo não-legítimo. Ele critica a diferenciação categórica que os autores fazem entre legitimidade e poder ao afirmar que há apenas legitimidade, sendo o poder apenas uma via para adquirila. O autor então sugere uma distinção entre legitimidade do stakeholder normativo e legitimidade do stakeholder derivativo para fornecer uma posição ao debate "perspectiva ampla versus perspectiva estrita" que reconheça simultaneamente as obrigações morais das organizações em 
relação a alguns grupos de stakeholders e a legitimidade pragmática baseada no poder, predominante da teoria das organizações e na sociologia. Sua distinção é embasada no princípio de eqüidade como fundamento normativo, formulado pelo autor da seguinte forma:

Sempre que pessoas ou grupos de pessoas aceitam voluntariamente os benefícios de um esquema mutuamente vantajoso de cooperação que requer sacrifício ou contribuição da parte dos participantes e que exista a possibilidade de free-riding, são criados obrigações de eqüidade entre os participantes no esquema cooperativo em proporção aos benefícios aceitos (PHILLIPS, 1997, p. 57).

Phillips (2007) explica que as obrigações em relação aos stakeholders surgem quando a organização aceita voluntariamente as contribuições de um grupo ou indivíduo. Diferentemente dos direitos humanos, por exemplo, em que se aceita as obrigações morais pela pessoa em si, as obrigações morais dos stakeholders são criadas sob a base das ações das partes. Essas obrigações são criadas entre as pessoas e as organizações internamente à esfera das associações privadas e não em âmbito da sociedade. Entretanto, o autor faz uma ressalva ao princípio normativo acima e afirma que seu limite está na interpretação do princípio da equiidade entre os stakeholders segundo a concepção estrita da teoria, ou seja, considera que apenas os grupos que possuem uma obrigação de eqüidade são os verdadeiros stakeholders.

Feitas essas considerações, Phillips (2007, p. 173) define stakeholder normativos como "aqueles a quem a organização tem uma obrigação moral, uma obrigação de eqüidade entre os stakeholders, superior aquele devido a outros atores sociais simplesmente em virtude de sua humanidade". O autor esclarece que quando não há uma obrigação para com um grupo em particular sob a categoria stakeholder não significa que a organização não tenha qualquer relação moral com tal grupo. Significa apenas que não haverá uma consideração moral adicional de equiidade entre os stakeholders a esses grupos na tomada de decisão gerencial e que a organização não tem qualquer obrigação de atender ao seu bem-estar.

Phillips (2007, p. 174) segue e define stakeholder derivativos como "aqueles grupos cujas ações e reivindicações devem ser levadas em conta pelos gerentes devido ao seu efeito potencial sobre a organização e seus stakeholders normativos". A legitimidade desses grupos está em sua capacidade de influenciar a organização e seus stakeholders normativos, ou seja, sua legitimidade não deriva de si mesmas, mas de sua influência potencial. Neste caso, não há qualquer obrigação moral da parte da organização de se preocupar com o seu bem-estar e podem ser tratados exclusivamente de forma instrumental (D'ORAZIO, 2006).

$O$ autor ainda define os nãostakeholders como grupos ou indivíduos em relação aos quais a organização não tem qualquer obrigação moral e a probabilidade deles terem um impacto sobre a organização ou em seus stakeholders legítimos é muito pequena. Dessa forma, é justificável omitir tais grupos e indivíduos da análise stakeholder.

A seguir é apresentado (Figura 1) um quadro geral das relações stakeholders segundo a tipologia de Phillips (2007). O autor chama a atenção para o caráter dinâmico do mapa - como nas considerações de Mitchell, Agle e Wood (1997) - cuja legitimidade stakeholder é sensível à natureza dinâmica das relações stakeholders. Uma das limitações desse modelo é a não inclusão do governo como um importante stakeholder derivativo.

Quanto à primeira questão, Philips (2007), Freeman e Wicks (2007) deixam claro que consideram um erro que a teoria dos stakeholders - apesar de ser utilizada primordialmente para organizações de grande porte e de controle difuso - seja 
restringida a um tipo e tamanho específicos de organização. Afirmam que a teoria pode e deve ser aplicada em empresas de pequeno porte, empresas familiares, empresas de controle não difuso, associações, organizações sem fins lucrativos ou públicas.

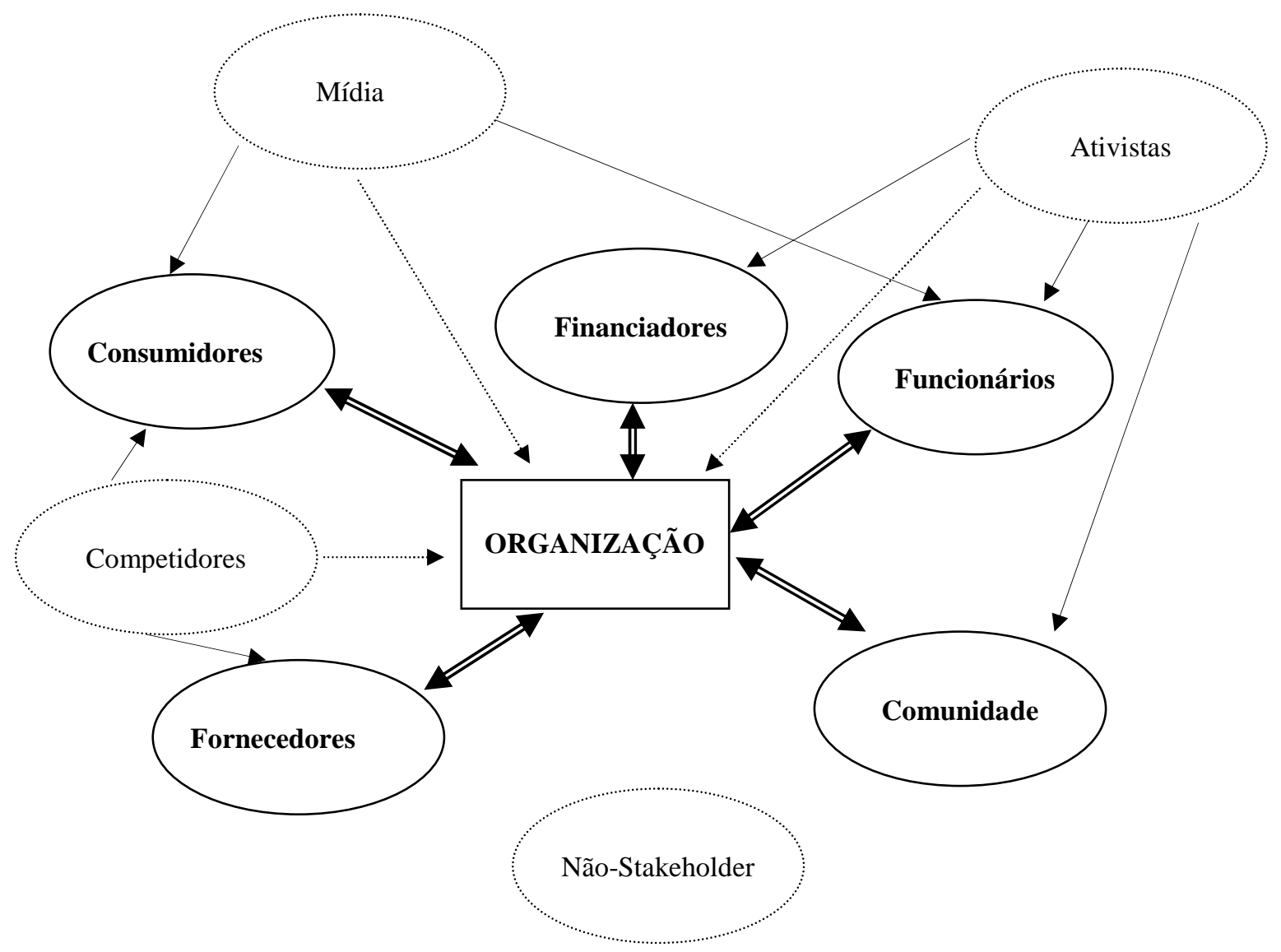

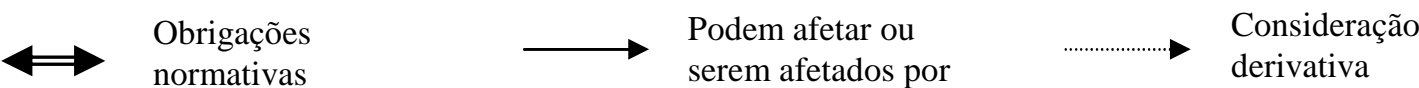

Figura 01 - Mapa dos stakeholders: normativos, derivativos e não-stakeholder.

Fonte: Phillips (2007, p. 181).

Apesar de Philips (2007), Freeman e Wicks (2007) não nomearem explicitamente organizações religiosas em seus argumentos, crê-se que a lista pode ser estendida sem problemas de modo a contemplá-la. Há ainda outro ponto que conta a favor do uso da teoria para as organizações religiosas e que está relacio- nado a uma pergunta subjacente: seria adequado que as organizações religiosas

fossem analisadas sob o ponto de vista do mercado?

4 Organizações religiosas e organizações econômicas: o argumento de Berger (2004) 
Como mencionado anteriormente, uma das características símiles da organização religiosa com a econômica é a sua situação de mercado. Mas isso se aplica ou é apenas em um sentido figurado? Berger (2004) propõe uma leitura bastante esclarecedora desta questão. Para o autor, a característica-chave de toda situação pluralística é a impossibilidade dos ex-monopólios religiosos de poderem contar com o seu público, ou seja, a submissão passou a ser voluntária e, portanto, não há mais a certeza de quantos membros ela conseguirá atrair e manter. Por conse-qüência, a tradição religiosa, que antes era imposta pela autoridade - seja governa-mental ou eclesial - agora deve ser colocada no mercado. Isso significa que ela deverá ser vendida para uma clientela que não é mais exclusiva e que precisa ser convencida a comprar seus bens e serviços religiosos. $\mathrm{E}$ em situação em que duas ou mais organizações com propósitos seme-lhantes procuram satisfazer as neces-sidades de um mesmo grupo de pessoas, estabelece-se a competição. Berger (2004, p. 149) afirma que "a situação pluralista é, acima de tudo, uma situação de mercado" e que, por isso, grande parte das atividades religiosas é regida pela lógica da economia de mercado, com as instituições religiosas se tornando agências de mercado $\mathrm{e}$ as tradições religiosas mercadorias de consumo, em um ambiente de competitividade.

Essa transformação das organizações religiosas, de monopólios a competidoras, levou também a transformações em suas estruturas sociais. Em situação de monopólio, as "estruturas sociorreligiosas" (ibidem., p. 150) não sofrem pressões para apresentar resultados, sendo as situações apresentadas incontestáveis per se. Em seu caráter competitivo, as estruturas sofrem pressões para que os resultados sejam apresentados, tais como - apenas para citar alguns - números de convertidos, milagres realizados, expansão numérica de igrejas e de membros, "resultados" das missões, das arrecadações, dos números de fiéis em eventos, capacidade de espetacularização, testemunhos apresentados, paz de espírito e melhora da situação de vida. E essa pressão por resultados, que pode servir de elemento comparativo para as pessoas que procuram uma organização religiosa, leva a uma "racionalização das estruturas sociorreligiosas" (ibidem., p. 150). Essa racionalização possibilitará que o objetivo organizacional seja cumprido de forma eficaz e que estratégias futuras sejam planejadas e colocadas em prática, expressando-se principalmente no fenômeno da burocracia (como em outras instituições da sociedade moderna).

Uma questão importante é que a expansão da burocracia possui a tendência de tornar as organizações religiosas parecidas em temos sociológicos, independentemente de suas tradições religiosas. Uma possibilidade é, por exemplo, duas organizações religiosas possuírem uma mesma estrutura, mas com duas legitimações teológicas diferentes uma da outra ou, ainda, possuírem funções burocráticas semelhantes com legitimações teológicas diferentes e até opostas, sem que a funcionalidade seja afetada. Berger (2004) torna mais precisa sua análise e chama a atenção que há na verdade diversos modelos de burocracia envolvidas nesse processo. Ele cita os casos das igrejas protestantes européias que, devido à longa experiência de igreja oficial, tendem para modelos políticos de burocracia, as igrejas protestantes americanas, que tendem a emular as estruturas burocráticas das empresas econômicas, e a igreja católica, que possui uma tradição própria de burocracia caracterizada por sua administração central. Apesar dessas diferenciações, Berger conclui que as exigências de racionalidade são semelhantes e exercem pressão em suas respectivas estruturas sociorreligiosas.

E continua Berger, a progressiva burocratização das organizações religiosas, 
inerente a sua situação contemporânea, faz com que as interações com outras organizações sigam o caráter burocrático, o que se traduz em "relações públicas" com a clientela, "lobbying" com o governo, "busca por financiamento" em agências privadas e governamentais, envolvimento com a economia secular (principalmente por meio de investimentos). A busca por resultados utiliza métodos muito semelhantes em relação a outras estruturas burocráticas que possuem o mesmo problema.

E como em qualquer burocracia, é fundamental que haja tipos específicos de pessoal. Por isso, "seleção e treinamento" surgem nas organizações religiosas, não apenas referente à formação de quadros religiosos - como padres, religiosos consagrados, bispos e pastores evangélicos - mas de pessoal técnico para levar a cabo de modo racional as exigências da burocracia. Nesse quadro, a tradição religiosa deixa de ser importante, sendo questão principal a adaptação ao papel burocrático, e devido a isso, há pouca importância de qual tradição religiosa o funcionário é proveniente. E para Berger, o tipo sóciopsicológico que surge na liderança de organizações religiosas é semelhante a de outras instituições burocráticas, cujas características são ser ativista, pragmático, hábil em relações interpessoais, alheio a qualquer reflexão administrativamente irrelevante, dinâmico e conservador ao mesmo tempo, entre outros.

A situação pluralista ainda cria o mercado competitivo e a concorrência para as organizações religiosas na medida em que se tornou impossível o emprego do braço político para a eliminação das rivais. Neste caso, a tendência do mercado religioso seria a de se tornar um sistema de livre competição se não fosse o fenômeno do "ecumenismo", num sentido estrito do termo. Para Berger (2004, p. 153), ecumenismo é uma "colaboração amigável cada vez mais estreita entre os diferentes grupos envolvidos no mercado religioso". E dependendo de certas afinidades, "os rivais religiosos são vistos não tanto como 'inimigos', mas como companheiros com problemas semelhantes". Nessa perspectiva, as igrejas neopentecostais possuem mais possibilidades de acordos entre si do que uma igreja neopentecostal e a igreja católica, ou entre uma igreja neopentecostal e uma igreja protestante histórica. Mas como Berger observa, a necessidade de colaboração se deve à necessidade de racionalização da competição na situação pluralista. Isso leva a uma tendência de que a competição por fiéis e recursos tenha certos limites para evitar a autodestruição e a elevação dos custos financeiros. Para a sobrevivência da organização ou sua expansão são necessárias ações que normalmente precisam de um capital razoável e ações no sentido de reduzir os riscos. Despesas com a administração burocráticas, despesas com a formação de pessoal, construção e manutenção de templos e igrejas, obras de caridade, produção de material promocional, veículos de comunicação (impressa, rádio, televisão e Internet), requerem somas de dinheiro que devem ser racionalmente empregados. As fontes de renda mais comuns, como doações e dízimos, são de difícil previsão e possui grau considerável de insegurança. E como afirma Berger, um modo de redução de riscos é conseguir o entendimento com os concorrentes, racionalizando a competição por meio da cartelização.

Até esse ponto foi abordada a influência que a situação pluralística exerce na estrutura sociorreligiosa. Entretanto, sua influência é mais abrangente e atinge também os conteúdos religiosos, ou seja, "o produto das agências religiosas de mercado" (ibidem, p. 156). Apesar dos conteúdos terem estado ao longo da história sempre sujeitas a influências mundanas, a situação pluralística introduz uma dinâmica nova: a preferência do consumidor. Como, relembrando, "a característica social e sociopsicológica crucial da situação pluralística é que a religião não 
pode mais ser imposta, mas tem que ser posta no mercado" (ibidem., p. 156), é fundamental que as necessidades e desejos da clientela sejam levados em consideração na oferta de algum bem ou serviço de consumo religioso. É certo que a tradição ainda tem o seu espaço e que haja "fidelidade ao produto" dos "velhos fregueses", mas as organizações religiosas precisam incorporar a solicitação de um público que possui certo grau de exigência sobre o produto. Dessa forma, a "dinâmica da preferência do consumidor" introduz a possibilidade de mudanças na esfera religiosa de um modo sem precedentes. Pode-se dizer que com a inserção dessa dinâmica moram numa mesma esfera dois inimigos, a mudança e o tradicionalismo, que as organizações religiosas deverão saber lidar com eles, a tensão entre eles e legitimá-los teologicamente.

Para Berger, a dinâmica da preferência do consumidor postula que os conteúdos substantivos estão suscetíveis à mudança, mas não determina a direção da mudança. Entretanto, há alguns fatores que condicionam o caráter dessa mudança. Um deles é o reflexo da secularização do mundo dos consumidores na preferência por produtos religiosos, significando que preferirão produtos religiosos que combinam com a sua consciência secularizada. Outra influência sobre o caráter da mudança vem da relevância socialmente significativa da religião. Como na Modernidade o significado da religião se situa principalmente na esfera privada, as preferências da clientela refletem as necessidades dessa esfera e o produto religioso terá mais chances de ser comercializado na medida em que atender essa preferência, ou seja, enfatizar que é mais relevante para a vida privada do que para as instituições públicas.

Berger (ibidem., p. 158) enfatiza que "daí resulta que as instituições religiosas tenham se acomodado às 'necessidades', moral e terapêutica, do indivíduo em sua vida privada". E isso pode ser evidenciado na ênfase que vem sendo dado à família, às questões psicológicas, à saúde física e financeira do indivíduo, e na "administração das emoções". E completa: "É nessas áreas que a religião continua a ser 'relevante' mesmo em camadas altamente secularizadas, enquanto a aplicação de perspectivas religiosas aos problemas políticos e econômicos é amplamente considerada 'irrelevante' nessas mesmas camadas" (ibidem., p. 158).

Berger ainda acrescenta mais dois efeitos do controle do consumidor sobre os conteúdos religiosos. $\mathrm{O}$ primeiro, a padronização, é a tendência de atender a necessidade que se apresenta razoavelmente homogênea dos membros atuais ou potenciais da organização. $\mathrm{O}$ autor exemplifica afirmando que uma organização religiosa orientada para o mercado da classe média alta nos Estados Unidos deverá secularizar e psicologizar seus produtos com o risco de, caso contrário, não conseguir vendê-los. O segundo efeito, denominado de diferenciação marginal, faz parte do processo de racionalização da concorrência e diz respeito à necessidade de se distinguir das outras organizações religiosas - aquelas que sobreviveram à cartelização - que oferecem produtos semelhantes devido ao efeito da padronização. Para Berger (2004), uma forma de diferenciação é a ênfase da "herança confessional", ou seja, assume-se um perfil de alguma tradição "redescoberta" e cria-se uma dinâmica da identificação e da autoindentificação. Atualmente, uma das formas de diferenciação e de influência na dinâmica da identificação é a utilização de técnicas de marketing, que cuidam, entre outras coisas, da "imagem institucional" da organização.

Ao se voltar para uma pergunta subjacente à questão dos stakeholders, qual seja, se seria adequado que as organizações religiosas fossem analisadas sob o ponto de vista do mercado, a argumentação de 
Berger (2004) parece suficiente para que se possa afirmar positivamente. E não apenas de forma figurada, mas como uma situação real de mercado competitivo capaz de influenciar as estruturas sociorreligiosas das organizações religiosas, devido à busca por resultados, e os conteúdos religiosos, por conta da dinâmica da preferência do consumidor. Essa situação de mercado deixa ainda mais confortável a possibilidade do uso da teoria dos stakeholders para as organizações religiosas, conforme será explorado nas conclusões a seguir.

\section{Conclusões: A teoria dos stakeholders aplica-se às organizações religiosas}

Tendo em vista a pergunta de pesquisa sobre a possibilidade de aplicação da teoria dos stakeholders às organizações religiosas, propõe-se a seguir um modelo de análise adaptado de Phillips (2007) para respondê-la. Além das adaptações de alguns stakeholders, foi acrescentado o governo como stakeholder derivativo e suprimido o stakeholder derivativo "ativistas" - cujo objetivo seria o de monitorar e exercer pressões sobre a organização - por ser considerado como não-stakeholder quando se trata de organizações religiosas. Adicionalmente, não é incomum que algumas dessas organizações religiosas sejam elas mesmas as ativistas de outras organizações. Ainda sobre o modelo, é possível que haja diferenciações no modelo stakeholder da igreja evangélica e da igreja católica devido ao grau diferenciado de orientação para o mercado.

Pelas características da situação de mercado em que as organizações estão submetidas, muitas semelhanças entre o modelo stakeholder de organizações econômicas e religiosas são inevitáveis, como explicitadas nas figuras anteriores. Entretanto, uma diferenciação bastante importante em relação à teoria dos stakeholders é a seguinte: enquanto a teoria busca se fundamentar em teorias éticas ou normativas para qualificar o relacio- namento organização-stakeholder, numa tentativa de inserir a dimensão ética na esfera econômica, nas organizações religiosas esse relacionamento é esperado - o que não significa que seja cumprido - de forma quase óbvia, principalmente pelo discurso moral dessas organizações. Em outras palavras, espera-se, ou melhor, confia-se que as ações organizacionais sejam mais éticas do que economicamente motivadas pelo critério normativo ser proveniente de base religiosa, o que significa uma responsabilidade moral intrínseca pelas conseqüências de suas ações em pessoas ou grupos afetados pelas suas atividades.

Quanto aos stakeholders normativos, as diferenciações mais marcantes entre a organização religiosa e econômica estão no relacionamento com os financiadores, funcionários, consumidores e comunidade. Para a organização religiosa, os financiadores são geralmente doadores, divididos em três categorias: (a) aqueles que fazem doações esporádicas e cujo valor pode variar entre pequenas quantidades de dinheiro e pequenos objetos a grandes quantidades de dinheiro e objetos de grande valor; (b) aqueles que fazem doações contínuas por meio de dízimos mensais; e, (c) aqueles que participam de campanhas caracterizadas por uma curta continuidade, como carnês para o financiamento de alguma obra social ou construção de templos e igrejas. Recentemente, algumas igrejas estão aderindo a parcerias com bancos privados e públicos para a concessão de cartões de crédito específico para os públicos evangélicos ou católicos e cujo objetivo é direcionar uma porcentagem do dinheiro arrecadado para os projetos sociais mantidos por essas igrejas. Outro ponto importante sobre os financiadores em relação ao retorno do valor doado (ou investido) é a sua dependência do desempenho da organização religiosa, assim como na organização econômica, e concretizados na melhoria física das igrejas e templos, na aquisição de equipamentos 
As organizações religiosas e suas relações: Uma análise a partir da teoria dos stakeholders

de áudio e vídeo, na melhoria e ampliação dos projetos sociais, entre outros. Porém, de um modo diverso, a organização não devolve o resultado do investimento nominalmente e apenas para os financiadores. 


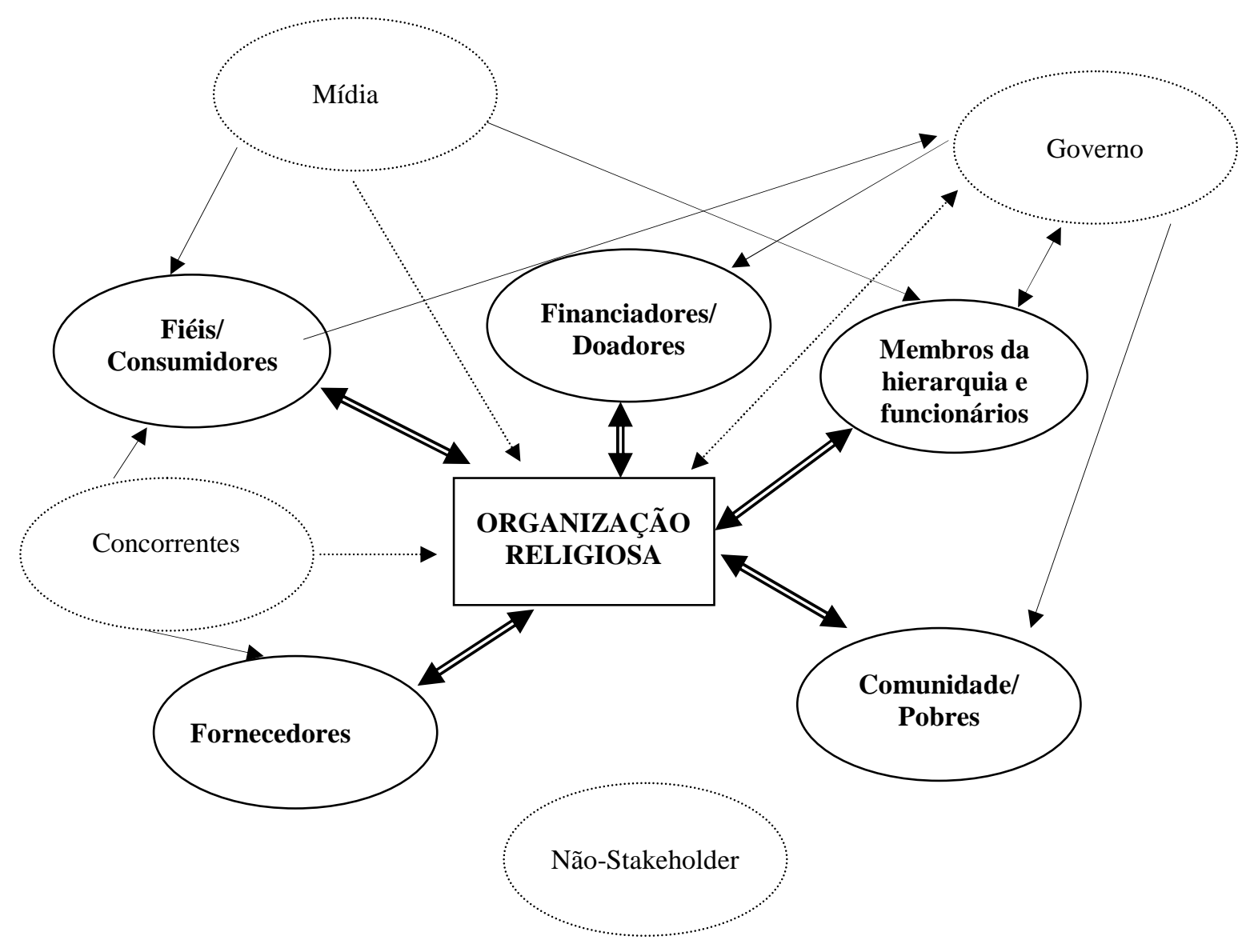

Obrigações normativas
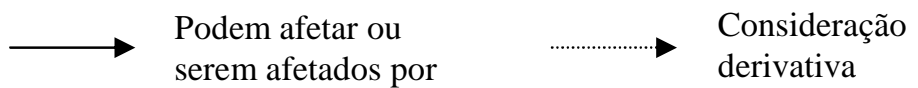

Figura 02 - Mapa dos stakeholders para as organizações religiosas.

Fonte: Adaptado de Phillips (2007, p. 181).

Por eles serem geralmente anônimos, o retorno provém de uma satisfação psicológica ao se sentir partícipe de uma organização em expansão e em desenvolvimento e, em algumas vezes, as doações vultosas garantem um "lugar especial" ou relacionamento privilegiado na hierarquia eclesial. Ou seja, existem formas diferenciadas de "retorno ao investidor" em termos de satisfação pessoal, status ou poder.
Quanto ao stakeholder funcionários, além do quadro de pessoal burocrático como há nas organizações, independentemente de seus objetivos, nas organizações religiosas há os membros da hierarquia eclesial, que podem exercer cargos burocráticos - o que acontece principalmente em postos de direção e em instâncias mais importantes de tomada de decisão revestidos, portanto, de uma legitimidade religiosa que outros funcionários burocráticos não possuem. Isso pode acarretar um hibridismo entre a dominação legal e a tradicional, no sentido weberiano, fazendo 
com que certas decisões sejam tomadas tendo como limites ou incentivos a maximização dos recursos ou suas estratégias e os valores morais e tradicionais cultivados pela organização.

Quanto ao terceiro stakeholder normativo, os consumidores/fiéis, da forma como foi descrita a dinâmica da preferência do consumidor, possuem semelhanças cada vez maiores com os consumidores de uma organização econômica, com a diferença que há um discurso legitimador para o usufruto de um bem ou serviço religioso. Uma das fontes dessa legitimação é o alto grau de confiança que os fiéis depositam naqueles que recomendam ou incentivam o consumo ou que oferecem o serviço. Outro ponto importante é que a obrigação moral com os consumidores vai além do aspecto stakeholder. Assim como se espera comportamento exemplar da hierarquia eclesial, espera-se uma atitude ética como comportamento padrão nos relacionamentos de compra e venda, sendo que qualquer comportamento fora desse padrão produz resultados mais danosos para uma organização religiosa do que para uma organização econômica porque atos desonestos são mais rigorosamente condenados e punidos: não se está ferindo apenas um contrato social, mas a confiança de uma comunidade religiosa.

No quarto stakeholder normativo, a comunidade, há uma saliência do pobre como um stakeholder importante que afeta e é afetado pelos objetivos da organização. Ela, a organização, possui valores normativos que orientam o seu relacionamento com o contexto social e econômico, e muitas delas possuem uma política de caridade e pobreza como ação organizacional, que a faz se diferenciar das organizações econômicas. Essas últimas podem ter ações direcionadas aos pobres, como os projetos de responsabilidade social ou iniciativas pessoais de proprietários e executivos, mas não fazem parte dos objetivos da organização.
Acerca do stakeholder concorrentes, a relação é um pouco mais complexa do que em uma organização econômica no livre mercado. O motivo dessa complexidade tem origens na discussão anterior sobre a tendência à cartelização. Há a tendência dos rivais no mercado religioso se considerarem mais como colegas com o mesmo problema do que como inimigos, em um clima de colaboração amigável, como afirmou Berger. No modelo, os concorrentes são considerados como stakeholders derivativos, mas se levarmos a argumentação de Berger a sério, o que temos é uma relação normativa com os concorrentes porque de certa forma há uma obrigação moral com os concorrentes. Certo que uma das motivações é a racionalidade econômica, de autopreservação, mas também há um componente valorativo, ou melhor, de solidariedade, quando uma organização religiosa enxerga os concorrentes como "estando na mesma situação". Isso é mais verdadeiro entre as igrejas protestantes e evangélicas e menos verdadeiro entre a igreja católica e as igrejas protestantes e evangélicas. Com efeito, o modelo deve ser revisto caso a caso e adaptado conforme a organização econômica que se está sendo investigada.

Uma limitação importante do uso da teoria dos stakeholders para a análise de organizações religiosas é indicado por Miller (2002). O autor sugere que nessas organizações as distinções entre os stakeholder são borradas porque a tecnologia de organizações religiosas normalmente envolve ação coletiva e, nesse caso, consumidores podem ser simultaneamente fornecedores e produtores.

\section{Referências}

BECKFORD, J. A. Religious organizations. In: SMELSER, N. J.; BALTES, P. B. (Eds.). International Encyclopedia of the Social \& Behavioral Sciences. Elsevier Ltd., 2004. Disponível em < 
http://www.sciencedirect.com/science/refer enceworks/9780080430768>.

BERGER, P. L. O dossel sagrado: Elementos para uma teoria sociológica da

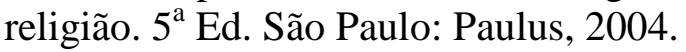

CHAVES, M. Religious organizations: Data resources and research opportunities. The American Behavioral Scientist, v. 45, n. 10, p. 1523-49, 2002.

CLARKSON, M. A stakeholder framework for analyzing and evaluating corporate social performance. Academy of Management Review, v. 20, n. 1, p. 853886, 1995.

DONALDSON, T.; PRESTON, L. E. The stakeholders theory of the corporation: concepts, evidence, and implications. Academy of Management Review, v. 20, n. 1, p. 65-91, 1995.

D’ORAZIO, E. (Org.). Business ethics and corporate social responsibility in a global economy. Notizie di Politeia, v. 20, n. 74, 2004.

D'ORAZIO, E. (Org.). New perspectives on the stakeholder view of the firm and global corporate citizenship. Notizie di Politeia, v. 22, n. 82, 2006.

D'ORAZIO, E. Verso una teoria normativa degli stakeholder. In: D'ORAZIO, E. (Org.). New perspectives on the stakeholder view of the firm and global corporate citizenship. Notizie di Politeia, v. 22 , n. 82,2006 . p. $40-59$.

FREEMAN, R. E. Strategic management: A stakeholder approach. Boston, Pitman, 1984.

FREEMAN, R. E.; REED, D. L. Stockholders e stakeholders: A new perspective on corporate governance. California Management Review, v. 25, n. 3, p. 88-106, 1983.

FREEMAN, R. E.; WICKS, A.; PARMAR, B.; MCVEA, J. Stakeholder Theory: The State of the Art and Future
Perspectives. In: D'ORAZIO, E. (Org.). Business ethics and corporate social responsibility in a global economy. Notizie di Politeia, v. 20, n. 74, 2004. p. 9-22.

FRIEDMAN, M. The social responsibility of business is to increase its profits. The New York Times Magazine, Sep. 13, 1970. p. 122-126.

GÖBEL, E. Stakeholder. In: BECKERT, J.; ZAFIROVSKI, M. (Ed.). Internacional Encyclopedia of Economic Sociology. London and New York: Routledge, 2006. p. 648-9.

GONÇALVES, J. C. S.; SERRA, A. R. C.; COSTA, C. E. S. A empresarização do sagrado: Um estudo sobre a estruturação de Igrejas Protestantes brasileiras. In: XXXI Encontro da ANPAD. Rio de Janeiro: ANPAD, 2007.

MARTINELLI, A. Foreword. In: D'ORAZIO, E. (Org.). New perspectives on the stakeholder view of the firm and global corporate citizenship. Notizie di Politeia, v. 22, n. 82, 2006. p. 5-6.

MILLER, K. D. Competitive strategies of religious organizations. Strategic Management Journal, v, 23, n. 5, p. 435456, 2002.

MITCHELL, R. K.; AGLE, B. R.; WOOD, D. J. Toward a theory of stakeholder identification and salience: defining the principle of who and what really counts. Academy of Management Review, v. 22, n. 4, p. 853-886, 1997.

OLIVEIRA, A. The place of spirituality in organizational theory. Electronic Journal of Business Ethics and Organization Studies, v. 9, n. 2, 2004.

PHILLIPS, R. A. Stakeholder theory and a principle of fairness. Business Ethics Quarterly, v. 7, n. 1, p. 51-66, 1997.

ZALESKI, P.; ZECH, C. The optimal size of a religious congregations. American Journal of Economics and Sociology, v. 54, p. 439-453, 1995. 